\title{
EFEK (FCEMNC) FAMILY CENTER EMPOWERMENT MODELION NUTRITION CHILDREN TERHADAP PENINGKATAN STATUS GIZI BALITA DI DESA SERUT KECAMATAN PANTI
}

\section{(EFFECT (FCEMNC) FAMILY CENTER EMPOWOREMENT MODELION NUTRITION CHILDREN AGAINST INCREASED NUTRITION STATUS CHILDREN IN SERUT VILLAGE PANTI DISTRICT)}

\author{
Larasmiati Rasman $^{1 *}$, Tria Permata Sari ${ }^{2}$, Latifa Aini ${ }^{3}$ \\ ${ }^{1,2,3}$ Fakultas Keperawatan, Universitas Jember \\ Jl. Kalimantan No. 37 Tegal Boto Jember Telp. /Fax. (0331) 323450 \\ *e-mail: Larasmiati29Rasman@gmail.com
}

\begin{abstract}
ABSTRAK
Keluarga dengan anggota keluarga yang mengalami suatu masalah kesehatan pasti dapat mempengaruhi sistem dalam keluarga tersebut. Family Center Empoworement Modelion Nutrition Children adalah salah satu intervensi berupa komunikasi terapeutik keluarga yang dibangun oleh anggota keluarga yang lain dengan anggota keluarga yang memiliki masalah kesehatan. Penelitian ini dilakukan untuk mengetahui pengaruh pengaruh Family Health Conversation terhadap peningkatan status gizi pada balita di Desa Panti, Jember. Desain penelitian ini adalah preeksperimental one grup, pre-post test dengan jumlah 9 keluarga sesuai dengan kriteria sampel sebagai keluarga mandiri tingkat 1. Hasil penelitian terdapat peningkatan tingkat kemandirian klien yaitu dari tingkat 1 ke tingkat 4 . Perlakuan selama 2 minggu secara intensif melakukan kunjungan 2 kali dalam seminggu, diketahui adanya pengaruh intervensi terhadap status gizi anak, yang dapat dilihat dari peningkatan berat badan. Komunikasi keterlibatan keluarga merupakan tehnik yang dibutuhkan untuk meningkatkan kemauan keluarga dalam mengupayakan adanya perubahan perilaku yang dapat menyelesaikan masalah kesehatan. Perlu dilaksbalita an sosialisasi pada perawat perkesmas dalam melakukan salah satu alternatif intervensi keperawatan keluarga dengan bentuk pengaruh Family Health Conversation
\end{abstract}

Kata kunci : Family Health Conversation, keperawatan keluarga

\section{ABSTRACT}

Families with family members who experience a health problem can definitely affect the system within the family. Family Center Empoworement Modelion Nutrition Children is one of the interventions of family therapeutic communication built by other family members with family members who have health problems. This study was conducted to determine the effect of Family Health Conversation on the improvement of nutritional status in toddlers in Panti Village, Jember. The design of this study is pre-experimental one group, pre-post test with 9 families in accordance with sample criteria as self-reliant level 1 families. Result of research there is increasing level of client independence that is from level 1 to level 4. Treatment during 2 weeks intensive visit 2 times in a week, the influence of intervention on the nutritional status of children, which can be seen from the increase in body weight. Family involvement communication is a necessary technique to increase the willingness of families in seeking behavioral change that can solve health problems. Need dilaksbalita an socialization on the nurse perkesmas in doing one alternative family nursing interventions with the form of influence Family Health Conversation

Keywords : Family Health Conversation, family nursing 


\section{PENDAHULUAN}

Keluarga merupakan unit pemeliharaan yang dapat menimbulkan, mencegah, mengabaikan atau memperbaiki masalah-masalah dalam kelompoknya. Masalah-masalah kesehatan dalam keluarga saling berkaitan dan apabila salah satu angota keluarganya mempunyai masalah kesehatan akan berpengaruh terhadap anggota keluarga yang lain [1].

Dalam keluarga, ibu memiliki peran penting dalam kesehatan balitanya. Masa balita merupakan fase terpenting dalam membangun fondasi pertumbuhan dan perkembangan manusia. Pada masa balita, status gizi secara langsung berpengaruh pada imunitas, perkembangan kognitif, pertumbuhan, dan stamina tubuh. Status gizi balita balita erat kaitannya dengan sistem imunitas tubuh dan status kesehatan. Status kesehatan balita ditentukan oleh perilaku sehat keluarga dan keadaan sanitasi rumah serta lingkungan sekitar. Makin rendah status gizi seseorang semakin rentan terhadap penyakit dan semakin tinggi tingkat morbiditas (Hardinsyah 2007).

Hasil Riset Kesehatan Dasar (Riskesdas) Kementerian Kesehatan 2010, 35,7 persen anak Indonesia pertumbuhan tingginya tidak sesuai dengan umur atau dalam kategori pendek. Riskesdas 2010 juga menemukan tingkat prevalensi gizi kurang pa da balita sebesar 17, 9 persen atau diperkirakan sekitar 3,7 juta balita mengalami

kekurangan gizi kurang dan gizi buruk (Yoedi, 2011). Dari hasil wawancara dengan Bidan Wilayah didapatkan data bahwa dari ketiga dusun yaitu dusun Mencek, Badean Kulon, dan Badean Wetan terdapat 5 balita di bawah garis merah (BGM). Selain itu juga terdapat balita dengan stunting dengan jumlah 60 balita. Hal ini membuktikan bahwa masih rendahnya pengetahuan ibu mengenai pentingnya pemenuhan gizi pada balita.

Faktor utama keberhasilan tumbuh kembang pada masa balita dipengaruhi oleh faktor gizi, kesehatan dan gaya pengasuhan orang tua yang terkait satu sama lain [2]. Pola asuh anak merupakan praktek pengasuhan yang diterapkan kepada anak balita dan pemeliharaan kesehatan. Pada masa balita anak belum dapat dilepas sendiri maka segala kebutuhan anak tergantung kepada orang tuanya.Tahun pertama kehidupan anak meru pakan dasar untuk menentukan kebiasaan di tahun berikutnya termasuk kebiasaan makan.

Menurut Soekirman (2000), pola asuhgizi merupakan perubahan sikap dan perilaku ibu atau pengasuh lain dalam hal memberi makan, kebersihan, memberi kasih sayang dan sebagainya dan semuanya berhubungandengan keadaan ibu dalam hal kesehatan fisikdan mental. Pola asuh yang baik dari ibu akan memberikan kontribusi yang besar pada pertumbunhan dan perkembangan balita sehingga akan menurunkan angka kejadian gangguan gizi. Ibu harus memahami cara memberikan perawatan dan perlindungan terhadap anaknya agar anak menjadi nyaman, meningkat nafsu makannya, terhindar dari cedera dan penyakit yang akan menghambat pertumbuhan. Apabila pengasuhan anak baik makan status gizi anak juga akan baik. Peran ibu dalam merawat sehari-hari mempunyai kontribusi yang besar dalam pertumbuhan anak karena dengan pola asuh yang baik anak

akan terawat dengan baik dan gizi terpenuhi.

\section{METODE}

Penelitian ini menggunakan desain pre eksperimental dengan pre-post test. Subyek penelitian ini adalah keluarga klien kelolaan di Desa Serut Kecamatan Panti, Jember. Teknik sampel yang digunakan adalah keluarga kelolaan dari pengumpul data yang dilakukan oleh 2 mahasiswa program profesi ners Program Studi Ilmu Keperawatan Universitas Jember yang terdiri dari 3 Keluarga yang diasuh oleh setiap mahasiswa keperawatan, sehingga terdapat 7 keluarga yang menjadi informan. Pengambilan data dalam penelitian ini 
dilaksbalita an di Desa Serut Kecamatan Panti pada bulan Mei - awal Juni tahun 2018 dengan cara perawat mendatangi rumah informan sebagai perawat keluarga dan menggunakan wawancara semiterstruktur dilakukan secara individu dengan masing-masing dari 7 anggota keluarga, kemudian dilakukan pengukuran terkait tentang pengalaman positif maupun pengalaman negatif merawat anggota keluarga yang sakit. Seluruh informan mendapatkan intervensi yang sama yaitu berupa Family Center Empoworement Modelion Nutrition Children yang dilakukan oleh anggota keluarga yang sehat selama satu jam setiap kegiatan dan dilakukan sebanyak 4 sesi selama 2 minggu yang dipimpin oleh 2 perawat keluarga yang datang ke masing-masing rumah keluarga, selanjutnya dilakukan evaluasi di akhir minggu setelah dilakukan intervensi Family Center Empoworement Modelion Nutrition Children. Etika penelitian pada penelitian ini meliputi informed consent, keadilan, kemanfaatan, keanoniman, dan kerahasiaan.

\section{HASIL}

Tabel 1. Distribusi Responden, Berat Badan, Tinggi Badan, dan Lila

\begin{tabular}{ccccc}
\hline Family & $\begin{array}{c}\text { Usia } \\
(\text { bln }) \\
\text { Jenis } \\
\text { Kelamin }\end{array}$ & $\begin{array}{c}\text { BB } \\
(\mathrm{Kg})\end{array}$ & $\begin{array}{c}\text { TB } \\
(\mathrm{cm})\end{array}$ & $\begin{array}{c}\text { Lila } \\
(\mathrm{cm})\end{array}$ \\
\hline A & $48(\mathrm{P})$ & 18 & 92 & 14 \\
\hline B & $36(\mathrm{~L})$ & 15 & 85 & 13 \\
\hline C & $12(\mathrm{~L})$ & 7 & 84 & 14 \\
\hline D & $29(\mathrm{P})$ & 10,3 & 86 & 14 \\
\hline E & $29(\mathrm{P})$ & 11 & 90 & 15 \\
\hline F & $31(\mathrm{~L})$ & 12 & 88 & 13 \\
\hline G & $10(\mathrm{P})$ & 8 & 83 & 14 \\
\hline Sumber : Data Primer (diolah Tahun 2018$)$
\end{tabular}

Hasil analisis pada tabel 1 menunjukan bahwa sebagian besar responden berjenis kelamin perempuan dengan jumlah responden sebanyak 7 orang balita dimana orangtua memiliki pekerjaaan petani atau buruh.

Tabel 2. Distribusi tingkat Kemandirian Keluarga

\begin{tabular}{lll}
\hline $\begin{array}{l}\text { Tingkat } \\
\text { Kemandirian }\end{array}$ & Pretest & Postest \\
\hline Pra mandiri & 0 & 0 \\
\hline Mandiri 1 & 7 & 0 \\
\hline Mandiri 2 & 0 & 0 \\
\hline Mandiri 3 & 0 & 7 \\
\hline Mandiri 4 & 0 & 0 \\
\hline \multicolumn{3}{l}{ Sumber : Data Primer (diolah Tahun 2018) }
\end{tabular}

Tabel 3. Distrubusi berat badan Sebelum dan Sesudah

\begin{tabular}{ccc}
\hline Nama & $\begin{array}{c}\text { Pre } \\
(\mathrm{Kg})\end{array}$ & $\begin{array}{c}\text { Post } \\
(\mathrm{Kg})\end{array}$ \\
\hline $\mathrm{A}$ & 18 & 20 \\
\hline $\mathrm{B}$ & 15 & 15 \\
\hline $\mathrm{C}$ & 7 & 9 \\
\hline $\mathrm{D}$ & 10,3 & 10 \\
\hline $\mathrm{E}$ & 11 & 11 \\
\hline $\mathrm{F}$ & 12 & 12 \\
\hline G & 8 & 15 \\
\hline
\end{tabular}

Sumber : Data Primer (diolah Tahun 2018)

Berdasarkan tabel diatas, terdapat perbedaan yang signifikan berat badan seluruh partisipan setelah pemberian intervensi.

\section{PEMBAHASAN}

Penelitian ini menggunakan 7 keluarga informan dan terbagi menjadi kelompok intervensi. Wawancara evaluatif semi terstruktur dilakukan secara individu dengan masing-masing dari 7 anggota keluarga dua minggu setelah mendapat pelatihan selama empat minggu dari perawat keluarga (pengumpul data). Dalam penelitian ini dimana seorang anggota keluarga dewasa yang mengalami masalah kesehatan ikut berpartisipasi dalam proses komunikasi terapeutik keluarga yang di pimpin oleh perawat keluarga (pengumpul 
data). Proses komunikasi terapeutik dilakukan selama 4 minggu di setiap keluarga. Terdapat 2 mahasiswa keperatan universitas Jember yang memimpin proses komunikasi terapeutik keluarga.

Pertemuan dilakukan 3 sesi dalam 6 minggu yang terdiri dari 2 perawat yaitu sebagai observer dan co participan dalam keluarga. Kegiatan ini fokus pada sebuah proses dari ketidaknyamanan peranan keluarga. Fungsi kegaiatan ini memberikan ruang untuk kepercayaan atau saling memberikan sebuah kepercayaan pada anggkota keluarga masing-masing, memberikan ruang untuk narasi yaitu memberikan kesempatan anggota keluarga untuk menyampaikan suatu pernyataan kepada anggota keluarga, memberikan kesempatan untuk mengutarakan kendala dalam perannya atau sesuatu yang lebih mendalam, memberikan kesempatan untuk keluarga mengkonfirmasi antar keluarga atas apa yang sudah diungkapkan sebelumnya. Kategori selanjutnya yaitu kesempatan untuk perubahan dalam keluarga dengan sub kategori memberikan waktu untuk refleksi yaitu mempersamakan persepsi nyata dari pernyataan yang sudah disampaikan oleh masing-masing keluarga. Sub kategori yang terakhir yaitu memberikan kesempatan untuk keluarga dalam menceritakan kendala atau masalah dalam perannya dan keluarga bersedia menerima keluhan tersebut.

Tingkat kemandirian pada awal sebelum adanya intervensi adalah tingkat kemandirian I, yaitu keluarga sudah mengakses pelayanan kesehatan tetapi keluarga belum terlibat dalam perawatan pada anggota keluarga yang mengalami masalah kesehatan. Selama 6 minggu dilakukan kunjungan dengan melakukan diskusi dan simulasi atau contoh perilaku yang dapat dilaksanakan keluarga dalam memberikan bantuan perawatan pada anggota keluarga yang mengalami masalah kesehatan keluarga didapatkan hasil bahwa $100 \%$ terdapat peningkatan kemandirian , menjadi keluarga mandiri III yaitu keluarga yang dapat terlibat aktif dalam melakukan perawatan pada anggota keluarga yang mengalami masalah kesehatan, adanya keterampilan untuk melakukan pencegahan masalah kesehatan atau menghindari adanya penularan penyakit dan adanya upaya keluarga untuk meningkatkan status kesehatan pada anggota keluarga. Bukti lain keberhasilan intervensi yaitu adanya peningkatan berat badan atau mempertahankan berat badan pada ke tujuh responden.

\section{SIMPULAN}

Berdasarkan hasil penelitian terdapat kesimpulan bahwa ada peningkatan kemandiran keluarga dari pemberian terapi Family Center Empoworement Modelion Nutrition Children dengan peningkatan status gizi pada balita di Desa Serut Kecamatan Panti, Jember.

\section{SARAN}

Saran yang direkomendasikan adalah diharapkan bahwa ada perawat khusus keluarga yang dapat mengelola keluarga terutama pada keluarga dengan masalah kesehatan dengan tujuan untuk meningkatkan status kesehatan dan kesejahteraan keluarga,

\section{UCAPAN TERIMA KASIH}

Peneliti mengucapkan terimakasih kepada pihak Puskesmas Panti Kecamatan Panti Kabupaten Jember, khususnya pada bidan tiap-tiap wilayah yang telah membantu dalam pelaksanaan penelitian ini.

\section{KEPUSTAKA AN}

[1] Notoatmodjo S. Promosi kesehatan teori dan aplikasinya. Jakarta: Rineka Cipta; 2010.

[2] Briawan D, Herawati T. Peran anggota rumahtangga di dalam pengasuhan pertumbuhan dan perkembangan balita balita. Laporan Akhir Penelitian Studi Kajian Wanita. Bogor: Fakultas Pertanian, Institut Pertanian Bogor.2005. 
[3] Diasmarani. Karakteristik dan Perkembangan Bahasa Balita Balita Stunted di Desa Sukawening Kabupaten Bogor.2010; [diunduh 2015 Feb 15]. Tersedia pada http://repository.ipb.ac.id

[4] [Riskesdas] Riset Kesehatan Dasar. 2013. Laporan hasil Riset Kesehatan Dasar Nasional 2013. [Internet]. [diunduh 2014 Okt 20]. Tersedia pada http//www.riskesdas.litbang.depkes.go. id. 